Review

\title{
Impact of a multidisciplinary approach in enteropathic spondyloarthritis patients
}

\author{
Paola Conigliaro a,1, Maria Sole Chimenti ${ }^{\mathrm{a}, 1}$, Marta Ascolani ${ }^{\mathrm{b}}$, Paola Triggianese ${ }^{\mathrm{a}}$, Lucia Novelli ${ }^{\text {a }}$, Sara Onali ${ }^{\mathrm{b}}$, \\ Elisabetta Lolli ${ }^{\mathrm{b}}$, Emma Calabrese ${ }^{\mathrm{b}}$, Carmelina Petruzziello ${ }^{\mathrm{b}}$, Francesco Pallone ${ }^{\mathrm{b}}$, \\ Roberto Perricone $^{\mathrm{a}, *}$, Livia Biancone ${ }^{\mathrm{b}}$
}

${ }^{a}$ Rheumatology, Allergology and Clinical Immunology, Department of Systems Medicine, University Tor Vergata, Rome, Italy

b GI Unit, Dpt. Department of Systems Medicine, University Tor Vergata, Rome, Italy

\section{A R T I C L E I N F O}

\section{Article history:}

Received 1 November 2015

Accepted 5 November 2015

Available online 7 November 2015

\section{Keywords:}

Enteropathic spondyloarthritis

Inflammatory bowel disease

Management

Multidisciplinary approach

\begin{abstract}
A B S T R A C T
Spondyloarthritis (SpA) and inflammatory bowel disease (IBD) are chronic autoinflammatory diseases that partially share the genetic predisposition and the unchecked inflammatory response linking the gut to the joints. The coexistence of both conditions in patients and the increased cross-risk ratios between SpA and IBD strongly suggest a shared pathophysiology. The prevalence of Enteropathic-related Spondyloarthritis (ESpA) in IBD patients shows a wide variation and may be underestimated. It is well accepted that the management of joint pain requires rheumatological expertise in conjunction with gastroenterologist assessment. In this view, we aimed at assessing, in a prospective study performed in a combined Gastro-Intestinal and Rheumatologic "GI-Rhe" clinic: (1) the prevalence of ESpA and other rheumatologic diseases in IBD patients with joint pain; (2) the features of the ESpA population; and (3) the diagnostic delay and the potential impact of the combined assessment. From November 2012 to December 2014, IBD patients with joint pain referring to a dedicated rheumatologist by the IBD-dedicated gastroenterologist were enrolled. Clinical and biochemical evaluations, joint involvement and disease activity assessment, diagnostic delay, and treatment were recorded. IBD patients $(n=269)$ with joint pain were jointly assessed in the "GI-Rhe" Unit. A diagnosis of ESpA was made in 50.5\% of IBD patients with joint pain. ESpA patients showed a peripheral involvement in $53 \%$ of cases, axial in $20.6 \%$ and peripheral and axial in $26.4 \%$ of cases. ESpA patients had a higher prevalence of other autoimmune extra-intestinal manifestations and received more anti-TNF treatment compared with IBD patients. A mean diagnostic delay of 5.2 years was revealed in ESpA patients. Patients with joint disease onset in the 2002-2012 decade had reduced diagnostic delay compared with those with onset in the 1980-1990 and 1991-2001 decades. Diagnostic delay was further reduced for patients with joint onset in the last two years in conjunction with the establishment of the GI-Rhe clinic. Multidisciplinary approach improved management of rheumatic disorders in IBD patients allowing a more comprehensive care.
\end{abstract}

(c) 2015 Elsevier B.V. All rights reserved.

\section{Contents}

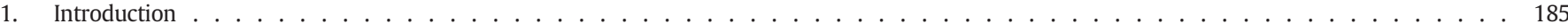

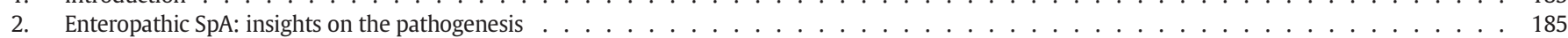

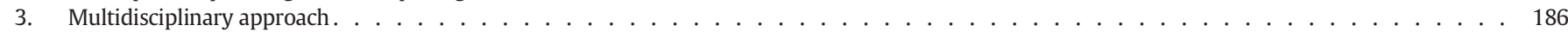

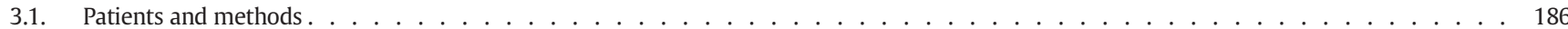

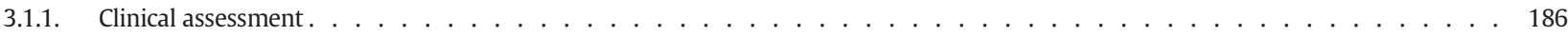

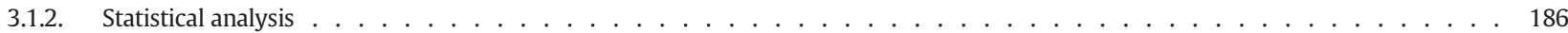

3.2. Results . . . . . . . . . . . . . . . . . . . . . . . . . . . . . 187

3.2.1. Rheumatologic diagnosis in patients with IBD . . . . . . . . . . . . . . . . . . . . . . . . 187

3.2.2. Clinical parameters in patients with ESpA . . . . . . . . . . . . . . . . . . . . . . . . . . . . . . . . . . . . . . . . 187

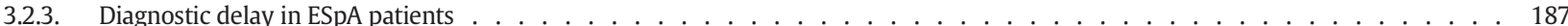

\footnotetext{
* Corresponding author at: Rheumatology, Allergology and Clinical Immunology, Department of “Medicina dei Sistemi”, University of Rome “Tor Vergata" Via Montpellier 1, 00163 Rome, Italy. Tel.: + 3906 72596287; fax: + 390620900358

E-mail address: roberto.perricone@uniroma2.it (R. Perricone).

1 Contributed equally to the study.
} 


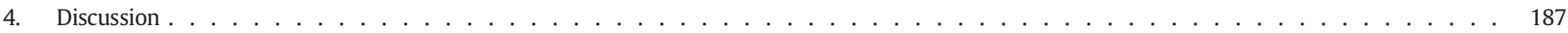

Take-home messages . . . . . . . . . . . . . . . . . . . . . . . . . . . . . . . . . . . . . . . . . . . . 189

Acknowledgment . . . . . . . . . . . . . . . . . . . . . . . . . . . . . . . . . . . . . . . . . . . . 189

References . . . . . . . . . . . . . . . . . . . . . . . . . . . . . . . . . . . . . . . 189

\section{Introduction}

Spondyloarthritis $(\mathrm{SpA})$ is a variety of inflammatory disorders that primarily affect entheses, small and large joints, and the axial skeleton joints [1]. This disease is characterized by the presence of inflammatory back pain - lumbar or buttock/hip pain lasting longer than 3 months associated with improvement with activity, worsening with rest, relief with non-steroidal anti-inflammatory drugs (NSAIDs), and morning stiffness lasting longer than 30 min [2]. The hallmark of SpA is inflammatory back pain while enthesitis, inflammation of tendonous or ligamentous insertions onto bone, is one of the most characteristic findings. SpA includes ankylosing spondylitis (AS), psoriatic arthritis (PsA), reactive arthritis, SpA associated with inflammatory bowel disease (IBD), non-radiographic axial (nr-ax) SpA and forms which do not meet criteria for the definite categories of $\mathrm{SpA}$ that are designated as undifferentiated SpA [3]. SpA pathogenesis is incompletely understood and the pathophysiological role of the synovium is just beginning to be elucidated. SpA is considered an enthesal disease and this hypothesis links mechanical stress (entheses) to immunologically active tissue (synovium) [4]. The Assessment in Spondyloarthritis International Society (ASAS) defined classification criteria considering SpA a distinct group of diseases with similar clinical features and a common genetic predisposition. As above mentioned, SpA frequently occurs in combination with other autoimmune conditions such as psoriasis, anterior acute uveitis, and IBD (Enteropathic SpA, ESpA) [5]. The ASAS-endorsed recommendations for early referral of patients suspected for having axial SpA by primary care physicians or non-rheumatologists include the extra-articular manifestations (psoriasis, IBD and/or uveitis) among the parameters for a diagnosis of SpA in patients with chronic low back pain (duration $\geq 3$ months) with onset before 45 years of age [6,7]. In 1998 the Oxford Criteria were proposed to classify the joint involvement in SpA patients with IBD including a type 1 peripheral arthritis that is the pauciarticular form involving fewer than 5 joints, a type 2 peripheral arthritis that is the polyarticular form involving 5 or more joints and a type 3 involvement with both axial and peripheral involvement $[8,9]$. Later, the joint involvement observed in IBD was usually classified mainly into two subsets: axial (including sacroileitis with or without spondylitis) and peripheral $[10,11]$. Evidence shows that the frequency of the joint involvement in IBD is affected by the criteria applied to define the clinical findings [12]. In particular, axial involvement is present in $2-16 \%$ of IBD patients and the prevalence of sacroileitis (asymptomatic and symptomatic) is $12-20 \%$, ranging from $3.9 \%$ to $18.9 \%$ when HLA-B27 is associated $[13,14]$. However, studies adopting the former European Spondyloarthropathy Study Group (ESSG) criteria for SpA detected a frequency ranging between 10-25\% for spondylitis and $30-36 \%$ for sacroileitis $[11,15]$. Overall the prevalence of ESpA in IBD shows marked variations (18-45\%) and may be underestimated by gastroenterologists [16]. Joint pain is a frequent and relevant clinical manifestation in IBD patients and its management requires rheumatologic expertise in conjunction with gastroenterologist. Flares of peripheral type 1 arthritis associated with IBD tend to occur with aggravation of the bowel disease, whereas the axial disease and peripheral type 2 arthritis tend to occur (and flare) independent of activity of intestinal inflammation [17]. Prompt diagnosis of rheumatologic diseases as SpA and PsA is necessary for the optimal patient management since the prevalence of undiagnosed disease remains high. Delay in diagnosis in turn delays introduction of appropriate disease-modifying treatment and may contribute to poor patient outcome [18]. Magnetic resonance imaging (MRI) is the gold standard for detecting sacroileitis in SpA patients [16]. Ultrasonography is a non-invasive and easily reproducible method of detecting early pathological changes in SpA patients [16]. It can identify characteristic features of SpA such as enthesitis, bone erosions, synovitis, bursitis, and tenosynovitis and is therefore helpful for diagnostic purposes. Laboratory abnormalities in SpA are nonspecific and not as useful as the clinical presentation for diagnosis of a specific disease. Patients often show nonspecific markers of inflammation including elevated $\mathrm{C}$ reactive protein (CRP), erythrocyte sedimentation rate (ESR), and normochromic normocytic anemia. However, elevated CRP is one of the criteria of ASAS classification for axial SpA [19]. Interestingly, elevated CRP is also a risk factor for radiographic progression together with tobacco smoking and the presence of syndesmophytes [20]. Nevertheless, specific and reliable biomarkers are needed [2]. HLA testing represents the most useful laboratory evaluation in appropriately selected patients. The recommendations for the treatment of active SpA included use of NSAIDs, use of TNF-inhibitors (TNF-i) when activity persists despite NSAID treatment, avoid systemic glucocorticoids, use of physical therapy and hip arthroplasty for patients with advanced hip arthritis [21]. No particular TNFi was suggested except in patients with concomitant IBD or recurrent iritis, in whom TNFi monoclonal antibodies should be preferred [21]. In patients with active nr-ax SpA despite treatment with NSAIDs, it is conditionally recommended treatment with TNFi [21]. There is little evidence of the efficacy of disease-modifying antirheumatic drugs (DMARDs) in SpA [22,23]. In controlled studies, sulfasalazine, methotrexate, and leflunomide have shown modest efficacy on the peripheral manifestations of AS, but the utility of these drugs in axial disease is unclear; therefore, DMARDs are not included as an alternative treatment in patients with ax-SpA refractory to NSAIDs [23].

\section{Enteropathic SpA: insights on the pathogenesis}

The association between SpA and IBD is largely established. The coexistence of both conditions in patients and the increased cross-risk ratios between SpA and IBD strongly suggest a shared pathophysiology [24]. Both the innate and adaptive immune responses are likely to contribute to the establishment of chronic inflammation [25]. An intricate cytokine milieu with a distinct contribution to systemic and joint inflammation has been described in SpA [26]. Evidence from genetics (the strong genetic association with the interleukin (IL)-23 receptor gene) and experimental models (e.g. the increased IL-17 production in HLA-B27 transgenic rats) strongly supports the involvement of the IL23/IL-17 axis in the pathogenesis of SpA [27]. Likewise, T helper (Th)17-related cytokines are produced in excess in Crohn's disease (CD) and ulcerative colitis (UC) tissue and it becomes evident that some Th17 cytokines have both proinflammatory and tissueprotective properties in IBD [28]. Although IL-23 was originally identified as a factor necessary for expanding/maintaining Th17 cells, recent studies have shown that IL-23 can also facilitate the deviation from a Th17 to a Th1 phenotype [29,30]. Moreover, IBD gene-wide association studies showed that polymorphisms of Th17-related genes, such as Stat3 or IL-23R, associate with IBD, supporting the involvement of the Th17 pathway into IBD pathogenesis [31]. HLA-B27 is involved in antigen presentation in the immune system and is thought to have a key role in the pathogenesis of the SpA. HLA-B27 recognizes an elevated prevalence in patients with AS, PsA, reactive arthritis, and ESpA but 
debated data have been reported in the studies [9,32]. ESpA pathogenesis, although initially linked to Th17, has been reported to be associated with innate like-T cell subpopulations that respond towards IL-23. These cells are present with a specific tissue distribution and could play a vital function in the development or progression of SpA-related pathology [33]. Moreover, there is evidence for increased IL-23 expression in inflamed tissues including the gut of SpA patients without an overt IBD [34]. Interestingly, IL-17 was not significantly upregulated in AS, nor were IL-6 and IL-1 $\beta$, whereas these cytokines were overexpressed in subjects with CD. Recent studies demonstrated that an uncontrolled activation and proliferation of innate lymphoid cells (ILCs) can contribute to severe inflammation and damage in gut, lung, and skin $[35,36]$. Gut interactions with the microbiome can influence natural killer (NK) cells and innate lymphoid immune responses in $\mathrm{SpA}$ and other related diseases, such as IBD. There is increasing genetic and functional evidence that ILCs contribute to the ROR $\gamma t$-driven inflammatory type 17 immune responses in SpA and they may link joint pathology with gut inflammation. Long-term evolution of subclinical gut inflammation to overt CD has been described in AS patients [37]. Moreover, an overexpression of IL-22, together with an increased number of IL-22-producing NKp44 + NK cells, has been described in the ileum of AS patients [38]. IL-22 is known to be regulated by IL-23 through lamina propria NKp44 + cells, which are thought to be regulators of homeostasis and tissue responses to infections and damage at mucosal surfaces [39]. More recently, gut-derived IL- $17^{+}$IL- $22^{+}$ILCs have been found expanded in the peripheral blood, synovial fluid and inflamed bone marrow of patients with AS, suggesting the presence of an active homing axis between the gut and the inflamed sacroiliac joints [40]. In addiction, the authors reported a significant decrease in the percentage of intestinal and circulating $\mathrm{IL}-17^{+} \mathrm{IL}-22^{+}$ILC and in the expression of mucosal vascular addressin cell adhesion molecule 1 (MADCAM-1) related to the TNFi treatment efficacy [40].

\section{Multidisciplinary approach}

ESpA may involve several tissues and organs being a potentially severe condition with multiple manifestations. Therefore, it requires a multidisciplinary approach coordinated by both the rheumatologist and the gastroenterologist. The combined assessment serves as tool that can improve the diagnostic and therapeutic management since the comprehensive care of SpA patients includes not only pharmacological treatment but also a tailored physical therapy [41,42].

On the basis of these observations, in a combined Gastro-Intestinal and RHEumatologic "GI-Rhe" clinic, we aimed to: (1) evaluate the prevalence of undiagnosed ESpA and other rheumatologic diseases in a cohort of IBD patients with joint pain; (2) characterize the clinical features of the ESpA population; and (3) analyze the diagnostic delay and the potential impact of the combined assessment.

\subsection{Patients and methods}

In a prospective study, from November 2012 to December 2014, all patients with established IBD showing musculo-skeletal pain with or without a known rheumatologic diagnosis were enrolled by the IBDdedicated gastroenterologist. Patients were referred to the combined GiRhe clinic of the University of Rome "Tor Vergata". Inclusion criteria: 1) Diagnosis of CD or UC made according to standard criteria $[14,43]$ and subgrouped in accordance with the Montreal classification [44] 2 ) age $>18$ and $\leq 80$ years; 3 ) available demographic and clinical data; 4) regular follow up at the referral IBD center of the University "Tor Vergata" of Rome, Italy; and 5) compliance to follow the study protocol.

Patients were referred by the IBD-dedicated gastroenterologist to the combined GiRhe clinic of the University of Rome "Tor Vergata". Demographic and clinical data, including gastrointestinal and rheumatologic characteristics and findings were recorded during the combined visit in a database shared by gastroenterologists and rheumatologists.
The following clinical information were included in the database: IBD duration, history of appendectomy, family history for IBD/psoriasis/ SpA, current/past smoking and extra-intestinal manifestations, such as erythema nodosum, uveitis, primary sclerosing cholangitis, cutaneous and nail psoriasis $[18,45]$.

\subsubsection{Clinical assessment}

New diagnosis, disease management, adverse events as well as laboratory evaluations were assessed during the medical evaluation. The total lag time from joint symptom onset to the first rheumatologic assessment, referred in the text as diagnostic delay, was recorded. The data were extracted from the medical records and referral letters in order to determine the time of disease onset and the following first visit to a rheumatologist. In a retrospectively designed analysis ESpA patients were arbitrary stratified according to the time of the joint involvement onset as follows: 1980-1990, 1991-2001, and 2002-October 2012. In a prospectively designed analysis ESpA patients with joint involvement onset from November 2012 to December 2014 were further divided: Nov 2012-Nov 2013 and Dec 2013-Dec 2014. The diagnostic delay was calculated for all patients and each patient was considered only once. Rheumatologic assessment included: physical examination with 68 tender and 66 swollen joint count, presence of dactylitis, enthesitis, inflammatory spinal pain and buttock pain. Laboratory test included ESR, CRP, uric acid levels, rheumatoid factor (RF), antinuclear antibodies (ANA), anti-citrullinated protein antibodies (ACPA) and HLAB27. Joint imaging was requested when appropriate such as ultrasound, traditional radiography and MRI. Active inflammatory lesions (primarily bone marrow oedema) and structural lesions (such as bone erosion, new bone formation, sclerosis and fat infiltration) were considered in MRI [46]. ASAS criteria were used in order to classify patients as affected by axial or/and peripheral SpA and by radiographic or nr-ax SpA [47]. The Oxford Criteria were used to classify the joint involvement in ESpA patients as follows: type 1 peripheral, type 2 peripheral and type 3 involvement (both axial and peripheral) $[8,9]$. The CASPAR criteria were used for psoriatic arthritis (PsA) [48], ACR criteria for Rheumatoid Arthritis [49] and EULAR/ACR criteria for Gout [50] Fibromyalgia and Osteoarthritis were diagnosed according with ACR and EULAR classification criteria [51,52]. Disease activity and function in SpA patients were assessed using the Ankylosing Spondylitis Disease Activity Score (ASDAS, CRP-based) [53,54], Bath Ankylosing Spondylitis Disease Activity Index (BASDAI) [55], Bath Ankylosing Spondylitis Functional Index (BASFI) [56], Disease Activity Score (DAS) and Health Assessment Questionnaire for SpA (HAQ-S) [57]. An ASDAS $\geq 2.1$ indicated high SpA disease activity [54].

$\mathrm{CD}$ and $\mathrm{UC}$ localization and $\mathrm{CD}$ behavior were registered according with current guidelines $[14,44]$. CD activity was evaluated using the CD Activity Index (CDAI) with a score $>150$ indicating active disease $[14,43]$. UC disease activity was measured by the partial Mayo score with a score $\geq 3$ indicating active disease according with the European Crohn's and Colitis' Organisation criteria [14]. The study was conducted in accordance with the ethical principles of the Declaration of Helsinki and was consistent with the guidelines for good clinical practice. Written informed consent was obtained from patients and the ethics committee approved the study.

\subsubsection{Statistical analysis}

To test normality of data sets the D'Agostino and Pearson omnibus test was used. Normally distributed variables were presented using mean and standard deviation (SD) while non-normally distributed variables were summarized with median and percentile ranges. Categorical variables were presented with absolute frequencies and percentages. Continuous variables were compared using the parametric unpaired $\mathrm{T}$ test or the nonparametric Mann-Whitney U test when appropriate. Categorical variables were compared using the Chi-squared test or Fisher' exact test when appropriate. The significance of any correlation was determined by Spearman's rank correlation coefficient. p values $<0.05$ 
were considered significant. All statistical analyses were performed using GraphPad Prism version 6 (GraphPad software).

\subsection{Results}

A total of 269 IBD patients with musculo-skeletal pain were evaluated in the combined GI-Rhe clinic between November 2012 and December 2014. The CD group included 166 patients and UC group included 103 patients. This cohort of IBD patients represented the $18 \%$ of a total of 1495 IBD patients evaluated in the same period in the IBDdedicated gastroenterology clinic. Characteristics of IBD patients with joint pain are summarized in Table 1 .

\subsubsection{Rheumatologic diagnosis in patients with IBD}

A diagnosis of a defined rheumatologic disease was performed in all IBD patients (Fig. 1A): ESpA was diagnosed in 136 patients (50.5\%), Osteoarthritis in 75 patients (27.9\%), Fibromyalgia in 15 patients (5.6\%), PsA in 10 patients (3.7\%), Rheumatoid Arthritis in 8 patients (3\%), and Gout in 4 patients (1.5\%). Other rheumatologic diseases were diagnosed in 21 patients (7.8\%) [mechanical low back pain $(\mathrm{n}=$ $5)$, Behçet disease $(n=4)$, Chondrocalcinosis $(n=4)$, Polymyalgia Rheumatica $(n=3)$, Aseptic Osteonecrosis $(n=2)$, Dupuytren's disease $(n=2)$, and De Quervain's disease $(n=1)]$. All the abovementioned rheumatologic diagnoses differ from ESpA and were referred in the text as IBD non-SpA.

Demographic and clinical features of ESpA patients $(n=136)$ were compared with those of IBD non-SpA patients $(n=133)$. No differences in age, gender, smoking habits, history of appendectomy, IBD diagnosis/ disease duration/disease activity, CD behavior, were detected between the two groups (data not shown). Other autoimmune extra-intestinal manifestations, such as psoriasis, uveitis, primary sclerosing cholangitis and erythema nodosum when grouped together showed a higher prevalence in ESpA patients (19.2\%) than in non-SpA patients $(6.8 \%$,

Table 1

Characteristics of patients with inflammatory bowel disease and joint pain in the study population.

\begin{tabular}{lll}
\hline & $\begin{array}{l}\text { Crohn's disease } \\
\mathrm{N}=166\end{array}$ & $\begin{array}{l}\text { Ulcerative colitis } \\
\mathrm{N}=103\end{array}$ \\
\hline Age (years) & $42.2 \pm 14.7$ & $48.7 \pm 14$ \\
Female (n/\%) & $108 / 65$ & $60 / 58.2$ \\
IBD disease duration (years) & $10.5 / 5-19.7$ & $9 / 6-18.5$ \\
Smokers (n/\%) & $81 / 48.8$ & $39 / 36.4$ \\
Clinically active IBD ${ }^{\mathrm{a}}$ (n/\%) & $24 / 14.5$ & $12 / 11.2$ \\
CRP (mg/dL) & $0.5 / 0-6.2$ & $0.8 / 0-6.2$ \\
ESR (mm/h) & $19 / 9-33$ & $16 / 7-31$ \\
CD localization (n/\%) & & $\mathrm{NA}$ \\
L1: ileum & $89 / 53.6$ & \\
L2: colon & $23 / 13.8$ & \\
L3: ileum-colon & $54 / 32.5$ & \\
L4: upper & $5 / 3$ & \\
CD behavior (n/\%) & & \\
B1: non-stricturing, non-penetrating & $83 / 50$ & \\
B2: stricturing & $74 / 44.6$ & \\
B3: penetrating & $10 / 6$ & \\
P: perianal disease & $18 / 10.8$ & \\
UC localization (n/\%) & & $19 / 17.8$ \\
Proctitis & NA & $24 / 23.3$ \\
Left colitis & & $52 / 50.4$ \\
Pancolitis & $26 / 15.7$ & $10 / 9.3$ \\
Family history ${ }^{\mathrm{b}}$ (n/\%) & $40 / 24$ & \\
Appendectomy (n/\%) & $22 / 13.3$ & \\
Extra-intestinal manifestations ${ }^{\mathrm{c}}$ (n/\%) & \\
\hline
\end{tabular}

Data are expressed as mean \pm SD or median/25th-75th percentiles. IBD: inflammatory bowel disease; CDAI: Crohn's disease activity index; CRP: C-reactive protein; ESR: erythrosedimentation rate; $\mathrm{CD}$ : Crohn's disease; UC: ulcerative colitis; NA: not applicable.

a Active IBD: $C D A I>150$ for $C D$; Mayo score $\geq 3$ for $U C$

b Psoriasis (CD 2/26), IBD (CD 24/26, UC 10/10).

c Extra-intestinal manifestations exclude the articular involvement. $\mathrm{p}=0.04)$. In particular, psoriasis resulted the more prevalent disorder in both groups (ESpA 12.5\% and IBD non-SpA 6\%), while other above mentioned manifestations were registered mainly in the ESpA group. Higher prevalence of pancolitis than left-sided colitis was observed in UC-ESpA patients (85\%) compared with UC-non-SpA ones $(62 \%, \mathrm{p}=$ 0.04). CD-non-SpA patients displayed a higher prevalence of ileal involvement (58.2\%) compared with that in CD-SpA patients (37.5\%, $\mathrm{p}=0.005)$. Regarding IBD treatments, use of anti-TNF- $\alpha$ treatments was more frequent in patients with ESpA than that in patients without SpA (35.6\% vs $16.3 \%, p=0.003$ ). The use of csDMARDs (conventional synthetic DMARDs) as monotherapy or combination and/or systemic steroids was similar in the two groups (data not shown).

\subsubsection{Clinical parameters in patients with ESpA}

ESpA patients were the $9 \%$ of the total 1495 IBD patients. Clinical and laboratory characteristics of IBD patients with ESpA are described in Table 2. Patients affected by ESpA presented a peripheral involvement in $53 \%$ of cases, an axial involvement in $20.6 \%$ of cases, and a type 3 involvement in $26.4 \%$ of cases. The prevalence of males was higher in patients with axial ESpA than in patients with peripheral and type 3 $\operatorname{ESpA}(\mathrm{p}=0.01$ and $\mathrm{p}=0.008$, respectively). ESpA disease duration was higher in axial ESpA patients compared with peripheral ESpA $(p=0.04)$. Peripheral arthritis was represented by a type 1 in $32 \%$ of patients and a type 2 in $68 \%$ of patients. $\mathrm{Nr}$-ax SpA was diagnosed in $32.3 \%$ of all ESpA patients: $57.1 \%$ in the axial ESpA group and $77.8 \%$ in type 3 ESpA group. Patients with axial ESpA showed higher CRP levels compared with patients with peripheral and type $3 \mathrm{ESpA}(\mathrm{p}=0.02$ for both comparisons). HLAB27 was positive in $16.2 \%$ of all ESpA patients with a similar proportion between axial and type 3 , while none of the peripheral ESpA patients resulted HLAB27 positive. In 46 cases (33.8\%) patients showed a high disease activity (ASDAS $\geq 2.1$ ). Axial ESpA patients had higher ASDAS compared with that observed in peripheral ESpA ones $(\mathrm{p}=0.03)$. BASDAI was higher in axial ESpA patients compared with that in both peripheral and type $3 \mathrm{ESpA}$ patients ( $p=0.02$ and $p=0.0001$, respectively) while it was higher in type $3 \mathrm{ESpA}$ patients than that in peripheral ones $(\mathrm{p}=0.009)$. Peripheral and type 3 patients showed higher DAS levels compared with those in axial patients ( $p=0.001$ for both comparisons). DAS was higher in UC-ESpA peripheral 2 patients compared with that in CD-ESpA peripheral 2 ones ( $p=0.001$ ) (Fig. 1B). Age, IBD type, BASFI, and HAQ-S were similar in all the groups of ESpA patients. No differences were observed in demographic and clinical parameters between CD-ESpA and UC-ESpA patients when considered both the whole population and according to the joint involvement. No correlations were found between DAS/ASDAS levels in peripheral 1 or $2 \mathrm{ESpA}$ patients and respective CDAI or Mayo score. Likewise, no differences were detected in CDAI or Mayo score between peripheral 1 and peripheral 2 ESpA patients.

\subsubsection{Diagnostic delay in ESpA patients}

ESpA patients displayed a mean diagnostic delay of 5.2 years. Patients were divided according to the onset of joint symptoms; those with joint symptoms onset in 2002-Oct 2012 had a reduced diagnostic delay compared with those patients with onset in the 1980-1990 and 1991-2001 ( $\mathrm{p}<0.0001$ for both comparisons) (Fig. 1C). Patients with articular onset between Dec 2013-Dec 2014 received an ESpA diagnosis earlier than those with onset between November 2012 and November 2013 ( $p=0.01$ ) (Fig. 1D). No differences in diagnostic delay resulted between axial, peripheral and type $3 \mathrm{ESpA}$ patients (Table 2).

\section{Discussion}

ESpA are a group of diseases with several manifestations requiring multidisciplinary approach. The primary goal of treating SpA patients is to maximize long term health-related quality of life through the control of inflammation, not only related to the joint but also to gut, skin and eye involvement. Prevention of progressive structural damage, 
A
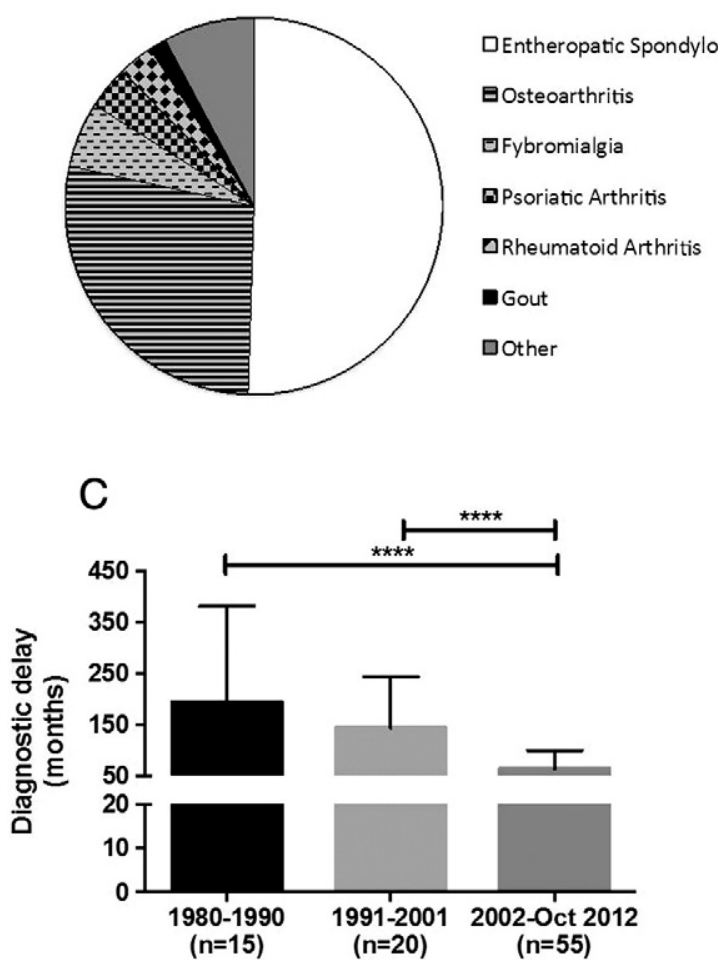

B

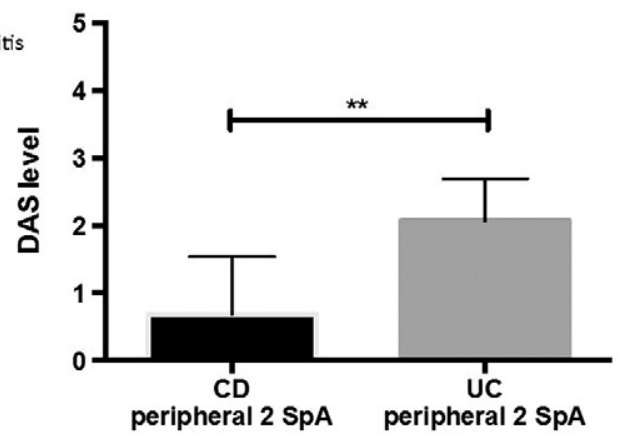

D

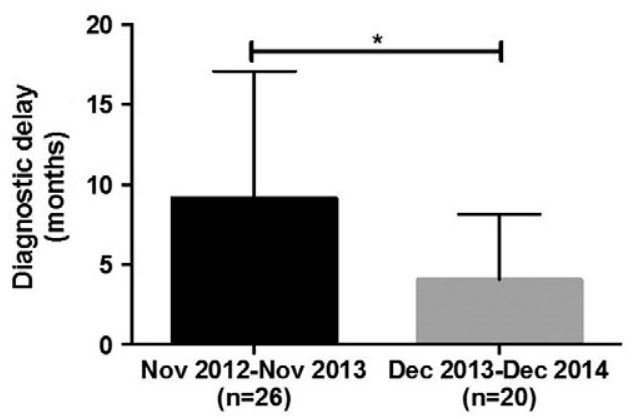

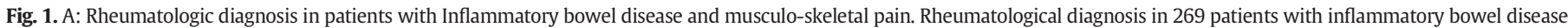

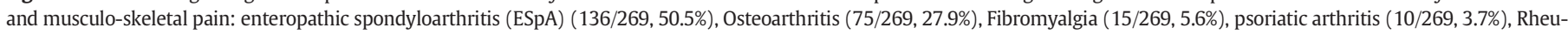

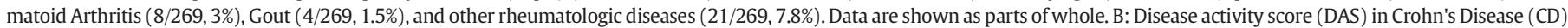

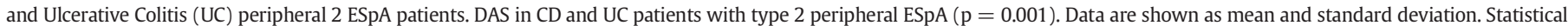

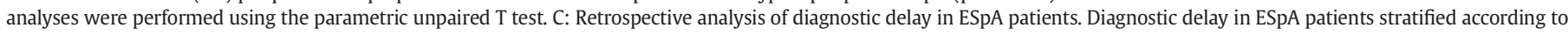

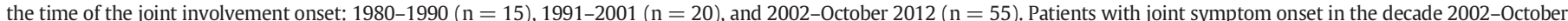

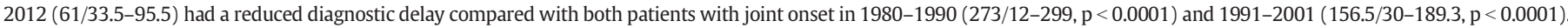

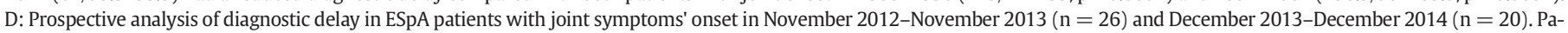

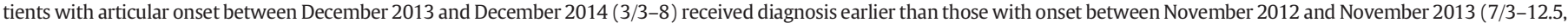
$\mathrm{p}=0.01$ ). Data in panels $\mathrm{C}-\mathrm{D}$ are shown as median with interquartile range. Statistical analyses were performed using the nonparametric Mann-Whitney U test.

preservation/normalization of function, and social participation are key points in treating to target patients affected by SpA [18]. Data from literature showed that the prevalence of peripheral arthritis in IBD patients varies from $11 \%$ to $20 \%$ and AS prevalence ranged from $3 \%$ to $6 \%$ [12]. In this study we demonstrated that joint involvement has a prevalence of $18 \%$ in a large cohort of 1495 IBD patients evaluated in the same period while ESpA has a prevalence of 9\%. Among the cohort of 269 IBD patients with musculo-skeletal pain, ESpA was diagnosed in $50.5 \%$ of cases, suggesting that most of IBD patients complaining joint pain may have a concomitant SpA. Our IBD study cohort with musculo-skeletal pain displayed a low prevalence of ileum-colon involvement and perianal disease than that described in the literature [14,43]. Other potentially debilitating rheumatologic diseases as Rheumatoid Arthritis, PsA and Aseptic Osteonecrosis were detected in the study population. Present findings support that evaluation in the GI-Rhe clinic significantly affects diagnosis and management of IBD patients at high risk of rheumatologic diseases. In this study we aimed at evaluating the epidemiology, the clinical pattern and the diagnostic delay of ESpA as few data are currently available, and most of them are translated from SpA or AS. Majority of ESpA patients were affected by type 2 peripheral involvement. Differently from previous studies, axial patients with ESpA showed a higher prevalence of male sex [58]. Higher CRP levels and longer disease duration were observed in axial ESpA patients compared with those detected in peripheral ESpA patients [59]. Concerning laboratory values, high CRP levels in ESpA patients may be mostly related to peripheral/axial joint inflammation, and not to clinical activity of IBD, being most of the patients in clinical remission maintained during the follow-up. This finding may be related to the observation that patients with ESpA were not hospitalized, as they were recruited in the outpatient clinic. A consistent number of ESpA patients (32.3\%) had a $\mathrm{nr}$-axSpA, consistent with the idea that the combined approach is useful for an early diagnosis of this disease. The $33.8 \%$ of ESpA patients showed joint disease clinically active. In particular, axial ESpA patients showed higher ASDAS levels than those in peripheral ones while DAS was higher in peripheral ESpA patients than that in axial ones, consistent with the prevalent joint involvement. Moreover, joint disease activity was neither related to IBD disease activity nor with IBD subtype, except for a higher DAS in UC-ESpA peripheral 2 patients with the respect to the $\mathrm{CD}$ ones. This finding may be related to immunosuppressive treatments used in $\mathrm{CD}$ patients that can affect joint disease activity. Comparison between demographic and clinical characteristics of ESpA and IBD non-SpA patients was then performed. When considering the prevalence of other autoimmune extra-intestinal manifestations, these manifestations were. It would be interesting in future studies to compare the frequency of extra-intestinal manifestations in ESpA patients and IBD patients without joint pain. In UC patients, pancolitis was more frequent in ESpA patients vs IBD non -SpA, as expected. Accordingly, in $C D$ patients ileal involvement was more frequent in IBD non-SpA vs ESpA patients [14,53,58]. When considering IBDrelated treatments, anti-TNF- $\alpha$ treatments at baseline were more frequent in patients with vs without ESpA. These findings suggest more aggressive luminal symptoms in IBD patients with SpA, including the presence of other comorbidities IBD-related that required this treatment. 
Table 2

Characteristics of enteropathic spondyloarthritis patients in the study population.

\begin{tabular}{|c|c|c|c|c|}
\hline & $\begin{array}{l}\mathrm{ESpA} \\
\mathrm{N}=136\end{array}$ & $\begin{array}{l}\text { Axial } \\
\mathrm{N}=28\end{array}$ & $\begin{array}{l}\text { Peripheral } \\
\mathrm{N}=72\end{array}$ & $\begin{array}{l}\text { Type } 3 \\
\mathrm{~N}=36\end{array}$ \\
\hline Age (years) & $46 \pm 10$ & $48 \pm 12.5$ & $45.5 \pm 14.2$ & $41.5 \pm 11$ \\
\hline Male (n/\%) & $45 / 33.1$ & $16 / 57.1^{\mathrm{ab}}$ & $21 / 29^{a}$ & $8 / 23^{b}$ \\
\hline CD (n/\%) & $88 / 64.7$ & $20 / 71.4$ & $47 / 65.3$ & $21 / 58.4$ \\
\hline UC (n/\%) & $48 / 35.3$ & $8 / 28.6$ & $25 / 34.7$ & $15 / 41.6$ \\
\hline $\begin{array}{l}\text { ESpA duration } \\
\text { (months) }\end{array}$ & $70 / 31.5-112.3$ & $67.5 / 6.2-179.3^{\mathrm{a}}$ & $34 / 8-96^{\mathrm{a}}$ & $70 / 31.5-112.3$ \\
\hline $\begin{array}{l}\text { Diagnostic } \\
\text { delay } \\
\text { (months) }\end{array}$ & $31 / 9-95$ & 18/6.2-95.7 & 25/8-95 & $60.5 / 12-92.7$ \\
\hline $\begin{array}{l}\text { Type } 1 \\
\text { peripheral } \\
(\mathrm{n} / \%)\end{array}$ & NA & NA & $23 / 32$ & NA \\
\hline $\begin{array}{l}\text { Type } 2 \\
\text { peripheral } \\
(\mathrm{n} / \%)\end{array}$ & NA & NA & $49 / 68$ & NA \\
\hline $\begin{array}{l}\mathrm{Nr}-\text { axial SpA } \\
\quad(\mathrm{n} / \%)\end{array}$ & $44 / 32.3$ & $16 / 57.1$ & $0 / 0$ & $28 / 77.8$ \\
\hline Enthesitis (n/\%) & $7 / 5.1$ & $4 / 14.3$ & $0 / 0$ & $3 / 8.3$ \\
\hline Dactylitis (n/\%) & $5 / 3.6$ & $0 / 0$ & $3 / 4.2$ & $2 / 5.5$ \\
\hline $\operatorname{ESR}(\mathrm{mm} / \mathrm{h})$ & $19 / 8.2-33.7$ & $16 / 9-50$ & $23 / 8-28$ & $19.5 / 11.7-36.5$ \\
\hline CRP $(\mathrm{mg} / \mathrm{dL})$ & $0.5 / 0.03-5.4$ & $1 / 0.06-13.7^{\mathrm{ab}}$ & $0.5 / 0-3.1^{\mathrm{a}}$ & $0.7 / 0.01-4^{\mathrm{b}}$ \\
\hline HLA-B27 (n/\%) & $22 / 16.2$ & $10 / 35.7$ & $0 / 0$ & $12 / 33$ \\
\hline ASDAS & $2.8 \pm 0.9$ & $2.9 \pm 0.9^{\mathrm{a}}$ & $2.1 \pm 1^{\mathrm{a}}$ & $2.9 \pm 1$ \\
\hline BASDAI & $3.8 / 1.1-6$. & $5.4 / 3.3-7.2^{\mathrm{ab}}$ & $0.8 / 0.2-3.3^{\mathrm{ac}}$ & $3.3 / 1.1-5.9^{\mathrm{cb}}$ \\
\hline BASFI & $1.4 / 0.4-4$ & $1.4 / 0.4-4$ & $0.6 / 0.1-2$ & $1.4 / 0.3-3.7$ \\
\hline DAS & $2.2 \pm 1$ & $1.1 \pm 0.7^{\mathrm{ab}}$ & $2.3 \pm 1^{\mathrm{a}}$ & $2.4 \pm 0.8^{\mathrm{b}}$ \\
\hline HAQ-S & $0.5 / 0.2-1.1$ & $0.6 / 0.1-1.1$ & $0.5 / 0.1-1.2$ & $0.5 / 0.2-1$ \\
\hline $\begin{array}{l}\text { Nr-axial SpA } \\
\quad(\mathrm{n} / \%)\end{array}$ & $44 / 32.3$ & $16 / 57.1$ & $0 / 0$ & $28 / 77.8$ \\
\hline Enthesitis (n/\%) & $7 / 5.1$ & $4 / 14.3$ & $0 / 0$ & $3 / 8.3$ \\
\hline Dactylitis (n/\%) & $5 / 3.6$ & $0 / 0$ & $3 / 4.2$ & $2 / 5.5$ \\
\hline
\end{tabular}

Data are expressed as mean \pm SD or median/25th-75th percentiles, unless differently specified. Type 3 indicates those patients with both axial and peripheral involvement. ESpA: enteropathic spondyloarthritis; CD: Crohn's disease; UC: ulcerative colitis; ESR: erythrosedimentation rate; CRP: C-reactive protein; ASDAS: Ankylosing Spondylitis Disease Activity Score; BASDAI: Bath Ankylosing Spondylitis Disease Activity Index; BASFI: Bath Ankylosing Spondylitis Functional Index; DAS: Disease Activity Score; HAQ-S: Health Assessment Questionnaire for SpA; NA: not applicable.

a Axial versus peripheral.

b Axial versus type 3 .

Peripheral versus type 3 .

We report a relevant diagnostic delay of 5.2 years in ESpA patients in accordance with previous reports in AS [60]. At the best of our knowledge, previous observations at this regard in patients with IBD are lacking. Several factors may contribute to this diagnostic delay such as the initial mild joint symptoms, the use of concomitant immunosuppressive therapies for IBD and the use of the New-York criteria that do not allow a definite diagnosis at disease onset [61]. The long diagnostic delay may also be related to a late referral to a rheumatologist by both the general practitioners and consulters due to a difficulty in recognizing SpA symptoms [9]. In this context, delay in the diagnosis or misdiagnosis may result in adverse outcome for patients as progression of joint damage and morbidity as observed in AS [60]. Data from literature suggest that SpA patients with short disease duration are more likely to respond to antiTNF- $\alpha$ treatment with a better disease outcome $[61,62]$. In patients with disease onset in the 2002-2012 decade, the diagnosis of ESpA was made earlier than in patients with disease onset in the previous decades. This is likely due to the more performing classification ASAS criteria and techniques of imaging like MRI and ultrasound that may reveal early inflammatory lesions of axial or peripheral joints [47]. In our study, a further reduction of diagnostic delay was observed in 2012-2014 in conjunction with the establishment of the GI-Rhe clinic. We can speculate that this result is also due to the combined approach where patients may benefit from a more comprehensive disease care. No difference in diagnostic delay was observed among the subtypes of ESpA maybe because of the small sample size. This observation might be explained by the immunosuppressive treatments used in patients with IBD for treating intestinal symptoms, also effective in reducing the joint disease activity hiding the symptoms.

Our population-based data support the concept that multidisciplinary care allows a proper and timely diagnosis and management of rheumatic disorders in IBD, thus offering a comprehensive treatment approach. A combined multidisciplinary approach may also lead to an early diagnosis and proper treatment and improve the outcome of chronic and debilitating arthropathies in patients with IBD.

\section{Take-home messages}

- Evidences from genetics and experimental models strongly support the involvement of the IL-23/IL-17 axis and more recently of the innate lymphoid cells in the pathogenesis of SpA.

- Multidisciplinary approach improves management of rheumatic disorders in IBD patients allowing a more comprehensive care.

- Treatment of ESpA should aim at optimal care and should be based on a shared decision between the patient and the rheumatologist.

- A tight and tailored follow up, in a combined management, should safeguard the evolution of disease activity towards the targeted goal.

- Delay in diagnosis, in ESpA, defers the introduction of appropriate disease-modifying treatment and contribute to poor patient outcome.

\section{Acknowledgment}

The authors would like to acknowledge Dr. Danila Giampaolo for the technical assistance.

\section{References}

[1] Dougados M, Baeten D. Spondyloarthritis. Lancet 2011;377:2127-37.

[2] Harper BE, Reveille JD. Spondyloarthritis: clinical suspicion, diagnosis, and sports. Curr Sports Med Rep 2009;8:29-34.

[3] Zeidler H, Amor B. The Assessment in Spondyloarthritis International Society (ASAS) classification criteria for peripheral arthritis and for spondyloarthritis in general: the spondyloarthritis concept in progress. Ann Rheum Dis 2011;70:1-3.

[4] Chimenti MS, Ballanti E, Perricone C, Cipriani P, Giacomelli R, Perricone R. Immunomodulation in psoriatic arthritis: focus on cellular and molecular pathways. Autoimmun Rev 2013;12:599-606.

[5] Breban M, Said-Nahal R, Hugot JP, Miceli-Richard C. Familial and genetic aspects of spondyloarthropathy. Rheum Dis Clin North Am 2003;29:575-94.

[6] van Hoeven L, Koes BW, Hazes JM, Weel AE. Evaluating the ASAS recommendations for early referral of axial spondyloarthritis in patients with chronic low back pain; is one parameter present sufficient for primary care practice? Ann Rheum Dis 2015. http://dx.doi.org/10.1136/annrheumdis-2015-208547 (pii: annrheumdis-2015208547).

[7] Poddubnyy D, van Tubergen A, Landewé R, Sieper J, van der Heijde D, Assessment of SpondyloArthritis international Society (ASAS). Development of an ASAS-endorsed recommendation for the early referral of patients with a suspicion of axial spondyloarthritis. Ann Rheum Dis 2015;74:1483-7.

[8] Orchard TR, Wordsworth BP, Jewell DP. Peripheral arthropathies in inflammatory bowel disease: their articular distribution and natural history. Gut 1998;42:387-91.

[9] Peluso R, Di Minno MN, Iervolino S, Manguso F, Tramontano G, Ambrosino P, et al. Enteropathic spondyloarthritis: from diagnosis to treatment. Clin Dev Immunol 2013;2013:631408

[10] Podolsky DK. Inflammatory bowel disease. N Engl J Med 2002;347:417-29.

[11] Xavier RJ, Podolsky DK. Unravelling the pathogenesis of inflammatory bowel disease. Nature 2007:448:427-34

[12] Salvarani C, Fries W. Clinical features and epidemiology of spondyloarthritides associated with inflammatory bowel disease. World J Gastroenterol 2009;15: 2449-55.

[13] Turkcapar N, Toruner M, Soykan I, Aydintug OT, Cetinkaya H, Duzgun N, et al. The prevalence of extraintestinal manifestations and HLA association in patients with inflammatory bowel disease. Rheumatol Int 2006;26:663-8.

[14] Dignass A, Lindsay JO, Sturm A, Windsor A, Colombel JF, Allez M, et al. Second European evidence-based consensus on the diagnosis and management of ulcerative colitis: current management. J Crohn's Colitis 2012;6:991-1030.

[15] Dougados M, van der Linden S, Juhlin R, Huitfeldt B, Amor B, Calin A, et al. The European Spondylarthropathy Study Group preliminary criteria for the Clinical and Developmental Immunology classification of spondylarthropathy. Arthritis Rheum 1991;34:1218-27.

[16] Atzeni F, Defendenti C, Ditto MC, Batticciotto A, Ventura D, Antivalle M, et al. Rheumatic manifestations in inflammatory bowel disease. Autoimmun Rev 2014; 13:20-3.

[17] Khan M. Update on spondyloarthropathies. Ann Intern Med 2002;136:896-907. 
[18] Smolen JS, Breedveld FC, Burmester GR, Bykerk V, Dougados M, Emery P, et al. Treating spondyloarthritis, including ankylosing spondylitis and psoriatic arthritis, to target: recommendations of an international task force. Ann Rheum Dis 2014 73:6-16.

[19] Van der Heijde D, Sieper J, Maksymowych W, Dougados M, Burgos-Vargas R, Landewé R, et al. 2010 update of the international ASAS recommendations for the use of anti-TNF agents in patients with axial spondyloarthritis. Ann Rheum Dis 2011;70 (8.5-905).

[20] Robinson PC, Brown MA. The window of opportunity: a relevant concept for axial spondyloarthritis. Arthritis Res Ther 2014;16:109.

[21] Ward MM, Deodhar A, Akl EA, Lui A, Ermann J, Gensler LS, et al. American College of Rheumatology/Spondylitis Association of America/Spondyloarthritis Research and Treatment Network 2015 recommendations for the treatment of ankylosing spondylitis and nonradiographic axial spondyloarthritis. Arthritis Rheum 2015. http://dx.doi.org/10.1002/art.39298.

[22] Chen J, Lin S, Liu C. Sulfasalazine for ankylosing spondylitis. Cochrane Database Syst Rev 2014;11, CD004800. http://dx.doi.org/10.1002/14651858.CD004800.

[23] Pontes C, Gratacós J, Torres F, Avendaño C, Sanz J, Vallano A, et al. Evaluation of dose reduction versus standard dosing for maintenance of remission in patients with spondyloarthritis and clinical remission with anti-TNF (REDES-TNF): study protocol for a randomized controlled trial. Trials 2015;16:370.

[24] Fantini MC, Pallone F, Monteleone G. Common mechanisms in inflammatory bowel disease and spondyloarthropathies. World J Gastroenterol 2009;15:2472-8.

[25] Nickdel MB, Conigliaro P, Valesini G, Hutchison S, Benson R, Bundick RV, et al. Dissecting the contribution of innate and antigen-specific pathways to the breach of self-tolerance in a murine model of arthritis. Ann Rheum Dis 2009;68:1059-66.

[26] Scrivo R, Conigliaro P, Riccieri V, Di Franco M, Alessandri C, Spadaro A, et al. Distribution of IL-10 family cytokines in serum and synovial fluid of patients with inflammatory arthritis reveals different contribution to systemic and joint inflammation. Clin Exp Immunol 2015;179:300-8.

[27] Yeremenko N, Paramarta JE, Baeten D. The interleukin-23/interleukin-17 immune axis as a promising new target in the treatment of spondyloarthritis. Curr Opin Rheumatol 2014:26:361-70.

[28] Geremia A, Biancheri P, Allan P, Corazza GR, Di Sabatino A. Innate and adaptive immunity in inflammatory bowel disease. Autoimmun Rev 2014;13:3-10.

[29] Zhou L, Spolski R, Min R, Shenderov K, Egawa T, Levy DE, et al. IL-6 programs T(H)17 cell differentiation by promoting sequential engagement of the IL-21 and IL-23 pathways. Nat Immunol 2007;8:967-74.

[30] Ahern PP, Schiering C, Buonocore S, McGeachy MJ, Cua DJ, Maloy KJ, et al. Interleukin-23 drives intestinal inflammation through direct activity on T cells. Immunity 2010;33:279-88.

[31] Anderson CA, Boucher G, Lees CW, Franke A, D'Amato M, Taylor KD, et al. Metaanalysis identifies 29 additional ulcerative colitis risk loci, increasing the number of confirmed associations to 47. Nat Genet 2011;43:246-52.

[32] Khan MA, Mathieu A, Sorrentino R, Akkoc N. The pathogenetic role of HLA-B27 and its subtypes. Autoimmun Rev 2007;6:183-9.

[33] Diani M, Altomare G, Reali E. T cell responses in psoriasis and psoriatic arthritis. Autoimmun Rev 2015;14:286-92.

[34] Ciccia F, Bombardieri M, Principato A, Giardina A, Tripodo C, Porcasi R, et al. Overexpression of interleukin-23, but not interleukin-17, as an immunologic signature of subclinical intestinal inflammation in ankylosing spondylitis. Arthritis Rheum 2009;60:955-65.

[35] Hazenberg MD, Spits H. Human innate lymphoid cells. Blood 2014;124:700-9.

[36] Yazdani R, Sharifi M, Shirvan AS, Azizi G, Ganjalikhani-Hakemi M. Characteristics of innate lymphoid cells (ILCs) and their role in immunological disorders (an update). Cell Immunol 2015;26. http://dx.doi.org/10.1016/j.cellimm.2015.09.006 (pii: S00088749(15)30018-6).

[37] Ciccia F, Accardo-Palumbo A, Rizzo A, Guggino G, Raimondo S, Giardina A, et al. Evidence that autophagy, but not the unfolded protein response, regulates the expression of IL-23 in the gut of patients with ankylosing spondylitis and subclinical gut inflammation. Ann Rheum Dis 2014;73:1566-74.

[38] Ciccia F, Accardo-Palumbo A, Alessandro R, Rizzo A, Principe S, Peralta S, et al. Interleukin-22 and interleukin-22-producing NKp44 + natural killer cells in subclinical gut inflammation in ankylosing spondylitis. Arthritis Rheum 2012;64:1869-78.

[39] Aparicio-Domingo P, Romera-Hernandez M, Karrich JJ, Cornelissen F, Papazian N, Lindenbergh-Kortleve DJ, et al. Type 3 innate lymphoid cells maintain intestinal epithelial stem cells after tissue damage. J Exp Med 2015;212:1783-91.

[40] Ciccia F, Guggino G, Rizzo A, Saieva L, Peralta S, Giardina A, et al. Type 3 innate lymphoid cells producing IL-17 and IL-22 are expanded in the gut, in the peripheral blood, synovial fluid and bone marrow of patients with ankylosing spondylitis. Ann Rheum Dis 2015;74:1739-47.

[41] Chimenti MS, Triggianese P, Conigliaro P, Santoro M, Lucchetti R, Perricone R. Selfreported adherence to a home-based exercise program among patients affected by psoriatic arthritis with minimal disease activity. Drug Dev Res 2014;75:S54-6.

[42] Conigliaro P, Triggianese P, Ippolito F, Lucchetti R, Chimenti MS, Perricone R. Insights on the role of physical activity in patients with rheumatoid arthritis. Drug Dev Res 2014;75:57-9.

[43] Dignass A, Van Assche G, Lindsay JO, Lémann M, Söderholm J, European Crohn's and Colitis Organisation (ECCO), et al. The second European evidence-based consensus on the diagnosis and management of Crohn's disease: current management. J Crohn's Colitis 2010;4:28-62.

[44] Satsangi J, Silverberg MS, Vermeire S, Colombel JF. The Montreal classification of inflammatory bowel disease: controversies, consensus, and implications. Gut 2006;17: 749-53.

[45] Román AL, Muñoz F. Comorbidity in inflammatory bowel disease. World J Gastroenterol 2011;17:2723-33.

[46] Mandl P, Navarro-Compán V, Terslev L, Aegerter P, van der Heijde D, D'Agostino MA et al. EULAR recommendations for the use of imaging in the diagnosis and management of spondyloarthritis in clinical practice. Ann Rheum Dis 2015;74:1327-39.

[47] Weber U, Zhao Z, Rufibach K, Zubler V, Lambert RG, Chan SM, et al. Diagnostic utility of candidate definitions for a positive MRI of the spine in patients with axial spondyloarthritis. Arthritis Rheum 2015;67:924-33.

[48] Taylor W, Gladman D, Helliwell P, Marchesoni A, Mease P, Mielants H, et al. Classification criteria for psoriatic arthritis: development of new criteria from a large international study. Arthritis Rheum 2006;54:2665-73.

[49] Aletaha D, Neogi T, Silman AJ, Funovits J, Felson DT, Bingham 3rd CO, et al. 2010 Rheumatoid arthritis classification criteria: an American College of Rheumatology/ European League Against Rheumatism collaborative initiative. Arthritis Rheum 2010;62:2569-81.

[50] Dalbeth N, Fransen J, Jansen TL, Neogi T, Schumacher HR, Taylor WJ. New classification criteria for gout: a framework for progress. Rheumatology (Oxford) 2013;52: 1748-53.

[51] Bennett RM, Friend R, Marcus D, Bernstein C, Han BK, Yachoui R, et al. Criteria for the diagnosis of fibromyalgia: validation of the modified 2010 preliminary ACR criteria and the development of alternative criteria. Arthritis Care Res 2014;66:1364-73.

[52] Zhang W, Doherty M, Peat G, Bierma-Zeinstra MA, Arden NK, Bresnihan B, et al EULAR evidence-based recommendations for the diagnosis of knee osteoarthritis. Ann Rheum Dis 2010;69:483-9.

[53] Braun J, van den Berg R, Baraliakos X, Boehm H, Burgos-Vargas R, Collantes-Estevez E, et al. 2010 update of the ASAS/EULAR recommendations for the management of ankylosing spondylitis. Ann Rheum Dis 2011;70:896-904.

[54] Lukas C, Landewé R, Sieper J, Dougados M, Davis J, Braun J, et al, Assessment of SpondyloArthritis international Society. Development of an ASAS-endorsed disease activity score (ASDAS) in patients with ankylosing spondylitis. Ann Rheum Dis 2009;68:18-24.

[55] Garrett S, Jenkinson T, Kennedy LG, Whitelock H, Gaisford P, Calin A. A new approach to defining disease status in ankylosing spondylitis: the Bath Ankylosing Spondylitis Disease Activity Index. J Rheumatol 1994;21:2286-91.

[56] Calin A, Garrett S, Whitelock H, Kennedy LG, O'Hea J, Mallorie P, et al. A new approach to defining functional ability in ankylosing spondylitis: the development of the Bath Ankylosing Spondylitis Functional Index. J Rheumatol 1994;21:2281-5.

[57] Daltroy LH, Larson MG, Roberts NW, Liang MH. A modification of the Health Assessment Questionnaire for the spondyloarthropathies. J Rheumatol 1990;17:946-50.

[58] Colombo E, Latiano A, Palmieri O, Bossa F, Andriulli A, Annese V. Enteropathic spondyloarthropathy: a common genetic background with inflammatory bowel disease? World J Gastroenterol 2009;15:2456-62.

[59] Braun J, Sieper J. Ankylosing spondylitis. Lancet 2007;369:1379-90.

[60] Salvadorini G, Bandinelli F, Delle Sedie A, Riente L, Candelieri A, Generini S, et al Ankylosing spondylitis: how diagnostic and therapeutic delay have changed ove the last six decades. Clin Exp Rheumatol 2012;30:561-5.

[61] Mau W, Zeidler H, Mau R, Majewski A, Freyschmidt J, Stangel W, et al. Clinical features and prognosis of patients with possible ankylosing spondylitis. Results of a 10-year followup. J Rheumatol 1988;15:1109-14.

[62] Rudwaleit M, van der Heijde D, Khan MA, Braun J, Sieper J. How to diagnose axial spondyloarthritis early. Ann Rheum Dis 2004;63:535-43. 